\title{
STUDIES OF CORONARY DISEASE IN THE EXPERIMENTAL ANIMAL. II. POLAROGRAPHIC DETERMINATIONS OF LOCAL OXYGEN AVAILABILITY IN THE DOG'S LEFT VENTRICLE DURING CORONARY OCCLUSION AND PURE OXYGEN BREATHING ${ }^{1}$
}

\author{
By J. J. SAŸEN, W. F. SHELDON, ORVILLE HORWITZ, PETER T. KUO, GEORGE \\ PEIRCE, HARRY F. ZINSSER, AND JOHN MEAD, JR. \\ (From the Robinette Foundation, Medical Clinic, Hospital of the University of Pennsylvania; \\ The Harrison Department of Surgical Research and the Department of Pathology, \\ Medical School of the University of Pennsylvania, Philadelphia, Penna.)
}

(Submitted for publication April 2, 1951; accepted June 25, 1951)

In experiments previously reported (1) it was found that platinum electrodes for polarographic measurement of oxygen availability have given fairly steady control readings in the left ventricular muscle of the dog. When the animals breathed pure oxygen, electrode readings rose 50-200\%. When a coronary branch was occluded they declined considerably at the borders of the ischemic area, approached zero at its center, and returned to the base line shortly after release of the ligature. If the artery was occluded with the dog breathing room air, pure oxygen breathing did not change values at the center of the ischemic area. However, it did cause a rise in the readings at the "borders" before the occlusion was released. These conclusions were based on studies of 12 anesthetized dogs using two or three electrodes simultaneously in each experiment.

We have since developed a more stable dog preparation, using larger numbers of electrodes and obtaining more frequent readings which give a more complete description of the changes in local oxygen availability during short periods of coronary occlusion. Our particular concern has been to learn the size of the "border" areas that may be favorably affected by oxygen inhalation as well as the magnitude and regularity of the oxygen effect. This paper will describe the method we now use, and present a statistical analysis of the results of the first seven experiments in which we have used it. These studies would seem to have a bearing on the

1 This investigation was supported by research grants from the National Heart Institute, of the National Institutes of Health, Public Health Service (USPH-398 and 392) and from the Life Insurance Fund for Medical Research. use of oxygen inhalation for the treatment of acute myocardial infarction in man.

\section{METHOD}

Apparatus. In our earliest experiments we used the polarographic apparatus described by Montgomery and Horwitz (2) for use in the skin. Since then certain modifications have been made. We now use continuous electrolysis with six to 10 electrodes in the circuit at all times, their individual current variations being recorded when desired on a D'Arsonval galvanometer with a sensitivity of $5 \times 10^{-10}$ amps. $/ \mathrm{mm}$. The circuit modification is shown in Figure 1 and described in its legend. Open tip platinum electrode construction and the principles of polarography as applied to animal tissues have been described by Davies and Brink (3) and Montgomery and Horwitz (4). For the indifferent electrode we have found it necessary to immerse the dog's entire hind foot in a glass dish of saturated $\mathrm{NaCl}$ solution from which contact is made to the salt bridge of a calomel half cell. For electrode connections to the switch box No. 30 plain enameled wire was further insulated by placing it inside vinyl tubing.

Anesthesia and gas administration. Healthy dogs weighing 15-22 Kgms. were given morphine sulfate intramuscularly ( $3 \mathrm{mg}$./ $\mathrm{Kgm}$.) followed in 45 minutes by slow intravenous injection of $0.25 \mathrm{cc}$. $/ \mathrm{Kgm}$. of a mixture containing equal parts of Nembutal $(60 \mathrm{mg} . / \mathrm{cc}$.) and Dial-Urethane (Ciba). This combination had the advantage of producing a relatively slow heart rate and no more than a moderate blood pressure fall. Pure oxygen or mixtures of oxygen and nitrogen were administered through a tracheal tube made to fit the trachea snugly by a balloon and connected to a breathing bag through a soda-lime cannister. The exhaust valve of the bag was left partly open for gas mixtures which were delivered with flows of 6-8 liters/minute.

Manual insufflation was carried on by intermittent pressure on the bag every 10-15 seconds from the time the thoracic cavity was opened till the end of the experiment.

Surgery. A sternum splitting incision was made, using aseptic technique only in the occasional animal for 


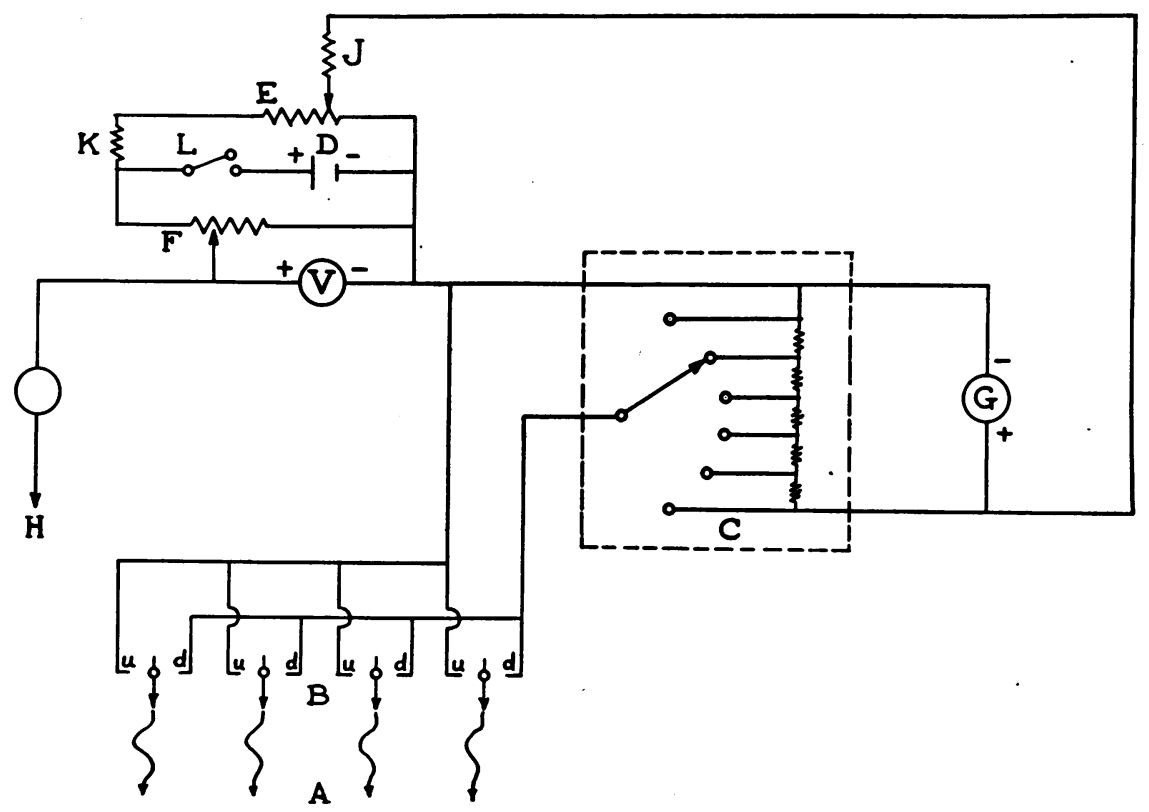

Fig. 1. Wiring Diagram of Circuit
A. Electrodes (cathodes)
B. Micro-switches
C. Ayrton shunt (Rubicon No. 1243), resistance 65,000 ohms
D. Dry cell (1.5 volts)
E. Variable resistance, $10,000 \mathrm{ohms}$
F. Variable resistance, $500 \mathrm{ohms}$
G. Galvanometer (Rubicon No. 3418)
H. Connection to calomel half-cell (anode)
J. Fixed resistance $(2,000,000 \mathrm{ohms})$
K. Fixed resistance $(40,000$ ohms $)$
L. Main switch
V. Voltmeter (1000 ohms per volt)
u. "Up" position (ordinary) of micro-switch
d. "Down" position.

The circuit described by Montgomery and Horwitz (4) has been modified by substituting micro-switches for the selector switch so that any number of electrodes in parallel (up to 10) may remain in the electrolysis circuit, the individual currents for each being read on the galvanometer by depressing (d) the micro-switch for the particular electrode. See text for connections of cathodes and anode to the animal.

which survival was planned. The pericardium was opened and stitched to the incision edges to form a cradle for the heart. One or two branches of the anterior descending coronary artery were dissected free from their accompanying veins and braided silk ligatures placed ready for traction. Warm saline was applied frequently to the heart.

Electrode placement. The tips of six to 10 electrodes were inserted through the epicardium 2-3 $\mathrm{mm}$. into the myocardium by simple pressure, each electrode resting lightly on the flange where its tip passed into the shaft, supported only by the wire which had been inserted into the mercury-filled glass shaft and covered by vinyl tubing. The wire arched from the electrode's butt to a rub- ber-shod Allis forceps at the incision's border (Figure 2), from which point of fixation it ran to the switch box. The simple arch of wire and vinyl tubing plus the weight of the electrode shaft proved superior to any more elaborate methods of support and enabled the electrodes to ride smoothly with the ventricular motion. Steady currents of the order of $10^{-7}$ amps. were recorded shortly after electrolysis at 0.6 volt was begun. If any electrode gave very low or irregular readings, the angle of insertion or the site was changed slightly, otherwise the electrodes were not touched during an experiment.

It proved best to start the animal breathing room air just after electrode insertion and to test the electrode sensitivity by a shift to pure oxygen, which caused all 


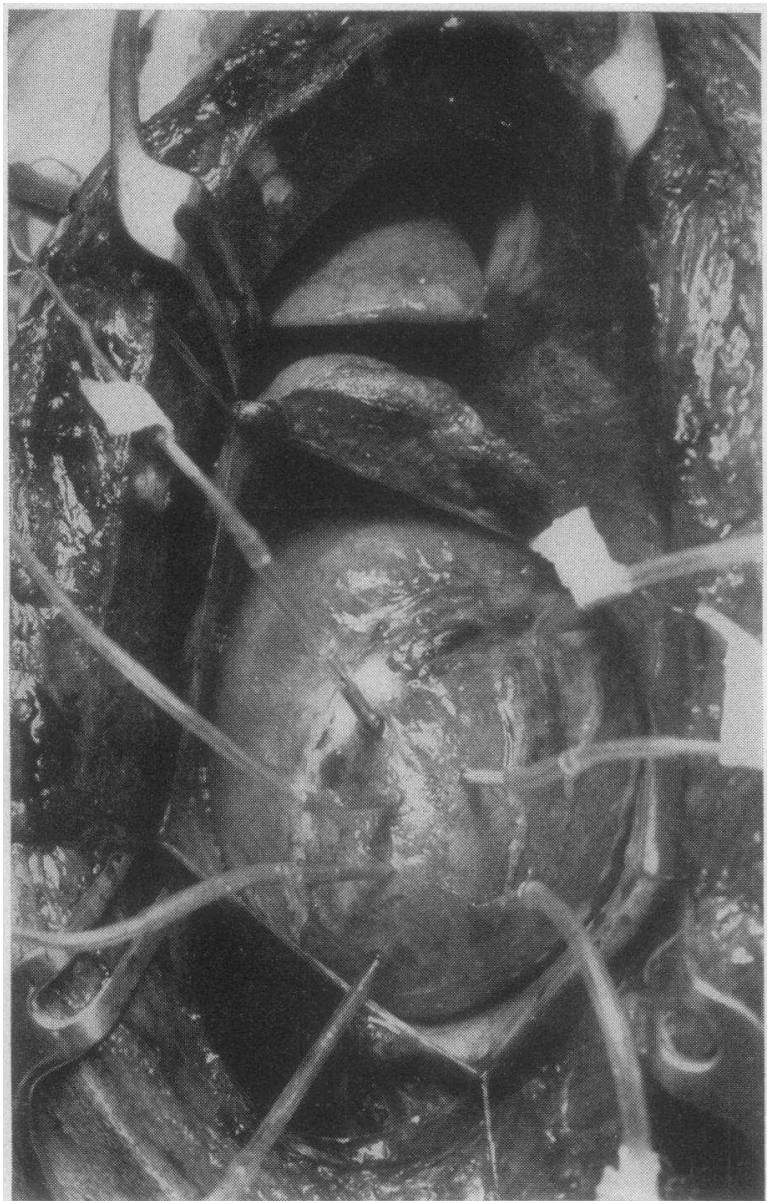

Fig. 2. Seven Electrodes Inserted in the Anterior Surface of a Dog's Left Ventricle During an ExPERIMENT

See text for a description of their connections and support. The head of the animal is beyond the upper margin of the picture. The sternum has been split and the heart is supported in a cradle of pericardium, sewn to the incision's edges.

values to rise barring mechanical or electrical faults. A drawing was then made of the topography of the exposed left ventricle including the major ramifications of all visible coronary branches and the sites of electrodes. Later, after observation of the effects of coronary occlusion, the distribution of cyanosis and systolic bulging were added to the drawing and the electrodes were classified on the basis of their apparent relation to the occluded coronary ramus and ischemic area as "center," "border" and "outside." Figure 3 shows the drawings for all seven experiments.

\section{Procedure}

(1) Control readings: Electrodes were read in rotation, six to nine seconds being required for galvanometer stabilization. The time at which each series of readings began was recorded. Before any occlusion or other procedure a base line was obtained on all electrodes consisting of three readings which did not differ in the case of any electrode by more than $15 \%$.

(2) Occlusion without oxygen: With strong traction occluding the coronary ramus, electrode readings were obtained during a three minute period and the two to five minutes required for return to a steady state after release.

(3) Occlusion, with oxygen before release: With the animal inhaling room air the coronary branch was again occluded and after at least two series of readings during the occlusion, $100 \%$ oxygen was substituted for air. The bag was flushed twice to facilitate the change. Two or three more series of readings were recorded and the occlusion was then released. The changes during the recovery period were studied for several minutes. Room air was then substituted for oxygen and additional readings were recorded.

\section{RESULTS}

The characteristic changes at 58 sites of insertion of the electrodes are summarized in Figure 4 and Table I. The division of electrodes into "center," "border" and "outside" groups was done as described above without reference to the electrode data. It can be seen that fairly good correlation exists between the distribution of the electrodes with respect to the visibly ischemic area and their types of behavior. The "central" electrode values drop sharply after coronary occlusion, their values remaining low until release regardless of oxygen breathing. Remote electrode readings show no statistically significant changes during or after occlusion except for their constant response to oxygen breathing. "Border" electrodes give figures similar to "central" electrodes except for a significant rise during oxygen breathing before termination of occlusion. During recovery from occlusion high values are recorded at all areas previously ischemic but there is no significant further rise at the "outside" electrodes. The post-occlusional increases in oxygen availability are greater at the "centers" of previously ischemic areas and after oxygen administration. With a combination of those circumstances the highest values were attained.

Records typical of the figures obtained from a "center," "border" and "outside" electrode during three occlusions without oxygen and two occlusions with oxygen before release are shown in Figure 5 . The absolute values recorded by the galvanometer have been converted into percentages of a repre- 

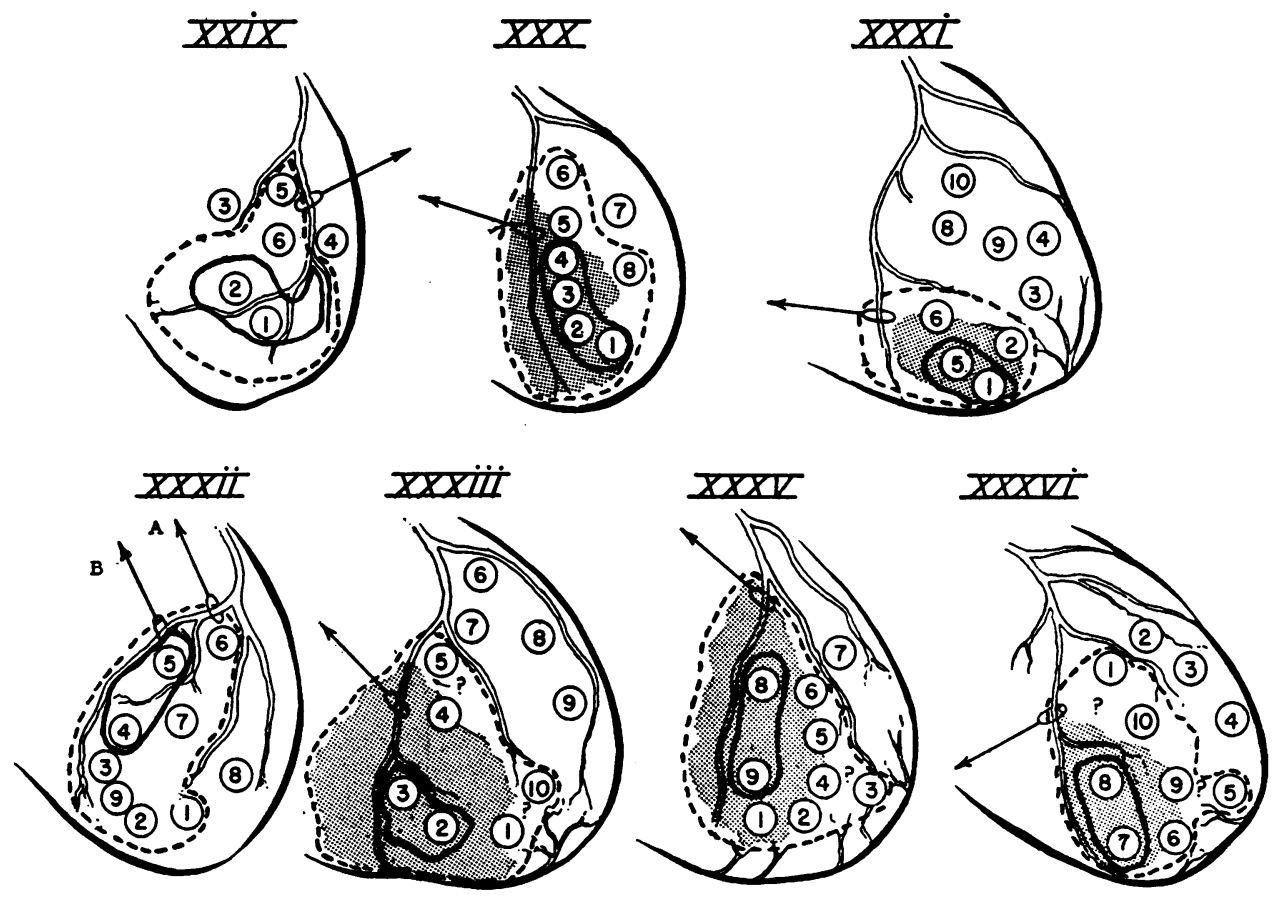

Fig. 3. The Position of Electrodes in Relation to the Coronary Vessels, Location of Ligature and Visible Extent of the Ischemic Area in Seven Experiments

In XXIX and XXXII no cyanosis or definite borders of the ischemic area could be seen although systolic bulging occurred in the distribution of the occluded coronary branches. Consequently there is a shaded region in only five of the drawings. The question marks in XXXIII, XXXV and XXXVI indicate areas of slight discoloration thought to be within the ischemic zone. The solid lines enclose the areas in which electrode positions were considered "central" on anatomic grounds for the purposes of the statistical analysis. The broken lines enclose the "border" electrode positions.

sentative initial base line reading for each electrode. The patterns of change in oxygen availability at each electrode with repeated occlusions of the same coronary ramus tended to be fairly constant. Longer occlusions caused larger changes to be recorded at "border" areas because of their slower rate of fall. "Center" electrodes tended to fall close to zero within three minutes of the beginning of occlusion. They were generally unaffected by oxygen breathing prior to the release of occlusion, whereas outside electrodes showed rapid rises and many "border" areas showed slighter but distinct rises. A minority of electrodes outside the ischemic area showed slight increases of oxygen availability during occlusion as shown by electrode No. 1 in Figure 5. Since muscle color and contraction seemed normal in such areas, the changes were thought to reflect increased circulation.

When no coronary occlusion was produced, rises in electrode currents with pure oxygen breathing were almost universal though the amount of rise varied widely. Failure of such a rise to occur was almost always attributable to some defect in an electrode or its connections. Slighter rises occurred with $50 \%$ oxygen breathing and falls below the base line occurred with $10 \%$ oxygen breathing, characteristics which will be reported in a later paper.

The effect on electrode values of parenteral epinephrine administration was comparable in direction and magnitude to that of pure oxygen inhalation. It appeared to be independent of the oxygen effect. These phenomena will be reported in detail later when the results of longer periods of observation can be evaluated. Ventricular fibrillation, which occasionally occurred at the end of an experiment, caused all electrode readings to drop rapidly to zero and remain there. 
TABLE I

\begin{tabular}{|c|c|c|c|c|c|c|}
\hline \multicolumn{7}{|c|}{ Occlusion, with oxygen before release } \\
\hline & $\begin{array}{l}\text { Number of } \\
\text { electrodes }\end{array}$ & $\begin{array}{l}\text { Base line } \\
\text { value }\end{array}$ & $\begin{array}{l}\text { (A) } \\
\text { Lowest } \\
\text { reading } \\
\text { during } \\
\text { occlusion }\end{array}$ & $\begin{array}{c}\text { (B) } \\
\text { Highest } \\
\text { reading } \\
\text { after } 100 \% \\
\text { oxygen and } \\
\text { before release }\end{array}$ & $\begin{array}{l}\text { (C) } \\
\text { Recovery }\end{array}$ & $\begin{array}{c}\text { Final steady } \\
\text { state }\end{array}$ \\
\hline $\begin{array}{l}\text { Center } \\
\text { Mean } \\
\text { Standard deviation }\end{array}$ & 22 & 100 & 12 & ${ }_{4.3}^{17}$ & 321 & 192 \\
\hline $\begin{array}{l}\text { Border } \\
\quad \text { Mean } \\
\text { Standard deviation } \\
\text { Outside }\end{array}$ & 41 & 100 & $\begin{array}{l}73 \\
8.1\end{array}$ & $\begin{array}{l}125 \\
14.7\end{array}$ & $\begin{array}{l}219 \\
24.9\end{array}$ & $\begin{array}{l}114 \\
7.4\end{array}$ \\
\hline $\begin{array}{l}\text { Mean } \\
\text { Standard deviation }\end{array}$ & 18 & 100 & $\begin{array}{l}97 \\
8.8\end{array}$ & $\begin{array}{c}185 \\
26.9\end{array}$ & $\begin{array}{l}298 \\
72.1\end{array}$ & $\begin{array}{c}134 \\
10.4\end{array}$ \\
\hline \multicolumn{7}{|c|}{ Occlusion without oxygen } \\
\hline $\begin{array}{l}\text { Center } \\
\quad \text { Mean } \\
\text { Standard deviation }\end{array}$ & 30 & 100 & $\begin{array}{c}14 \\
3.1\end{array}$ & & $\begin{array}{l}149 \\
10.1\end{array}$ & $\begin{array}{l}106 \\
3.2\end{array}$ \\
\hline $\begin{array}{l}\text { Border } \\
\text { Mean } \\
\text { Standard deviation } \\
\text { Outside }\end{array}$ & 48 & 100 & $\begin{array}{l}72 \\
6.2\end{array}$ & & $\begin{array}{l}129 \\
5.8\end{array}$ & $\begin{array}{l}109 \\
5.2\end{array}$ \\
\hline $\begin{array}{l}\text { Mean } \\
\text { Standard deviation }\end{array}$ & 31 & 100 & $\begin{array}{l}88 \\
11.1\end{array}$ & & $\begin{array}{l}113 \\
8.3\end{array}$ & $\begin{array}{l}97 \\
4.2\end{array}$ \\
\hline
\end{tabular}

Readings selected from central, border and outside electrodes, the last base line reading being taken as $100 \%$ : (A) The reading showing the largest change from the base line during occlusion, (B) the highest value during oxygen administration before release, (C) the highest value during the first three minutes of recovery from occlusion, and (D) the final reading after the animal had again been stabilized on room air. Standard deviations are given for the mean values in each instance.

TABLE II

Physiological classification of electrode areas

\begin{tabular}{|c|c|c|c|c|c|c|c|}
\hline & \multirow{2}{*}{$\begin{array}{l}\text { Total } \\
\text { number of } \\
\text { occlusions } \\
\text { with or with- } \\
\text { out oxygen }\end{array}$} & \multirow{2}{*}{$\begin{array}{l}\text { Number of } \\
\text { occlusions } \\
\text { with oxygen } \\
\text { before } \\
\text { release }\end{array}$} & \multirow{2}{*}{$\begin{array}{l}\text { Number of } \\
\text { electrodes }\end{array}$} & \multicolumn{4}{|c|}{ Mean oxygen effects before release } \\
\hline & & & & $\begin{array}{l}\text { Rise over } \\
25 \%^{*}\end{array}$ & $\underset{\text { 5-25\% }}{\text { Rise }}$ & $\begin{array}{l}\text { Rise less } \\
\text { than } 5 \%^{*}\end{array}$ & Falls \\
\hline $\begin{array}{l}\text { Group I } \\
\text { "Center" } \\
\text { Mean fall to below one-fourth of } \\
\text { base line value }\end{array}$ & 50 & 22 & 14 & 1 & 2 & 8 & 3 \\
\hline $\begin{array}{l}\text { Group II } \\
\text { "Border" } \\
\text { Significant mean fall but less } \\
\text { than Group I }\end{array}$ & 91 & 44 & .28 & 14 & 5 & 4 & 5 \\
\hline $\begin{array}{l}\text { Group III } \\
\text { "Outside" } \\
\text { Mean fall } \dagger \text { less than 15\%* }\end{array}$ & 56 & 25 & 16 & 11 & 3 & 0 & $2 \ddagger$ \\
\hline
\end{tabular}

* Of the pre-occlusion base line value.

$\dagger$ Rises occurred at seven electrodes.

These falls followed large rises during occlusion.

The left half of this table shows a classification of all electrode areas based on the mean fall during occlusion and before oxygen (if given). The three groups, which are "center," "border" and "outside" areas physiologically, are not incompatible with the anatomic areas seen in Figure 3.

The approximate magnitude (in terms of the pre-occlusion base line value taken as $100 \%$ ) and the frequency of pre-release rises in response to inhalation of pure oxygen are given for the three physiological groups in the right-hand half of the table. 


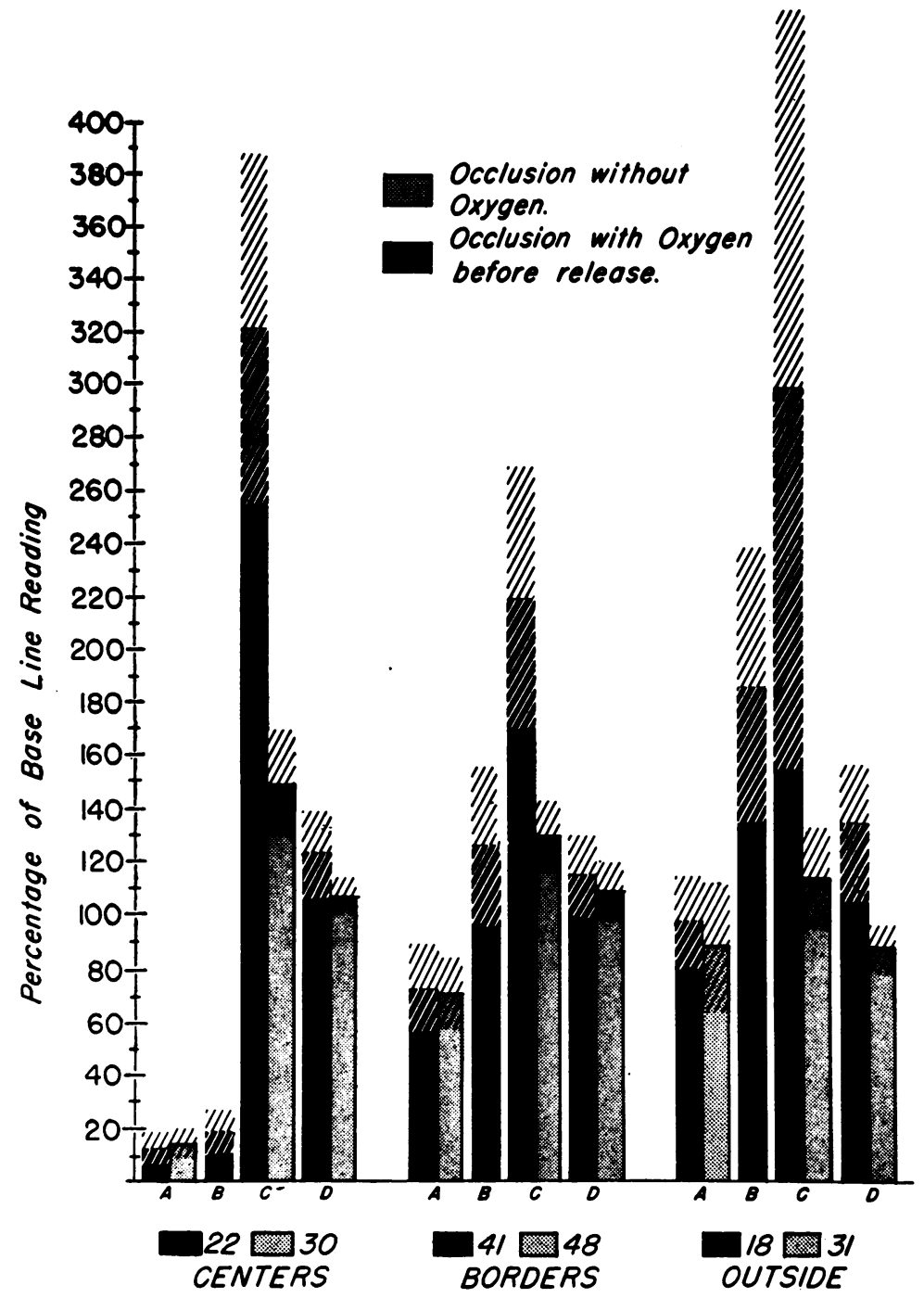

Fig. 4. Bar Graph of the Mean Values Given in Table I

The two types of occlusion are distinguished by black and gray, while the cross-hatchings represent twice the standard deviation of values above and below the mean for each group of determinations, the number of these in each case being given below the graph. The initial base line readings are not given since they were taken as $100 \%$. The paired or single bars for each group of electrodes correspond to columns two through five of Table I: that is, (A) maximum fall with occlusion, (B) change with oxygen before release, (C) recovery, (D) return to steady state. Note especially the means of border electrodes at (A) and (B) and the significant difference between them.

\section{DISCUSSION}

Open tip platinum electrodes provide relative measurements of oxygen tension in homogeneous solutions (3). In the heart muscle, because a constant relationship between tension and diffusion of oxygen cannot be assumed, it is probably prefer- able to report the electrode measurements in terms of oxygen "availability." We have departed from the method used for skin by Montgomery and Horwitz (4) in which brief closures of the circuit presumably cause only short gradients of oxygen tension out from the electrodes with less 


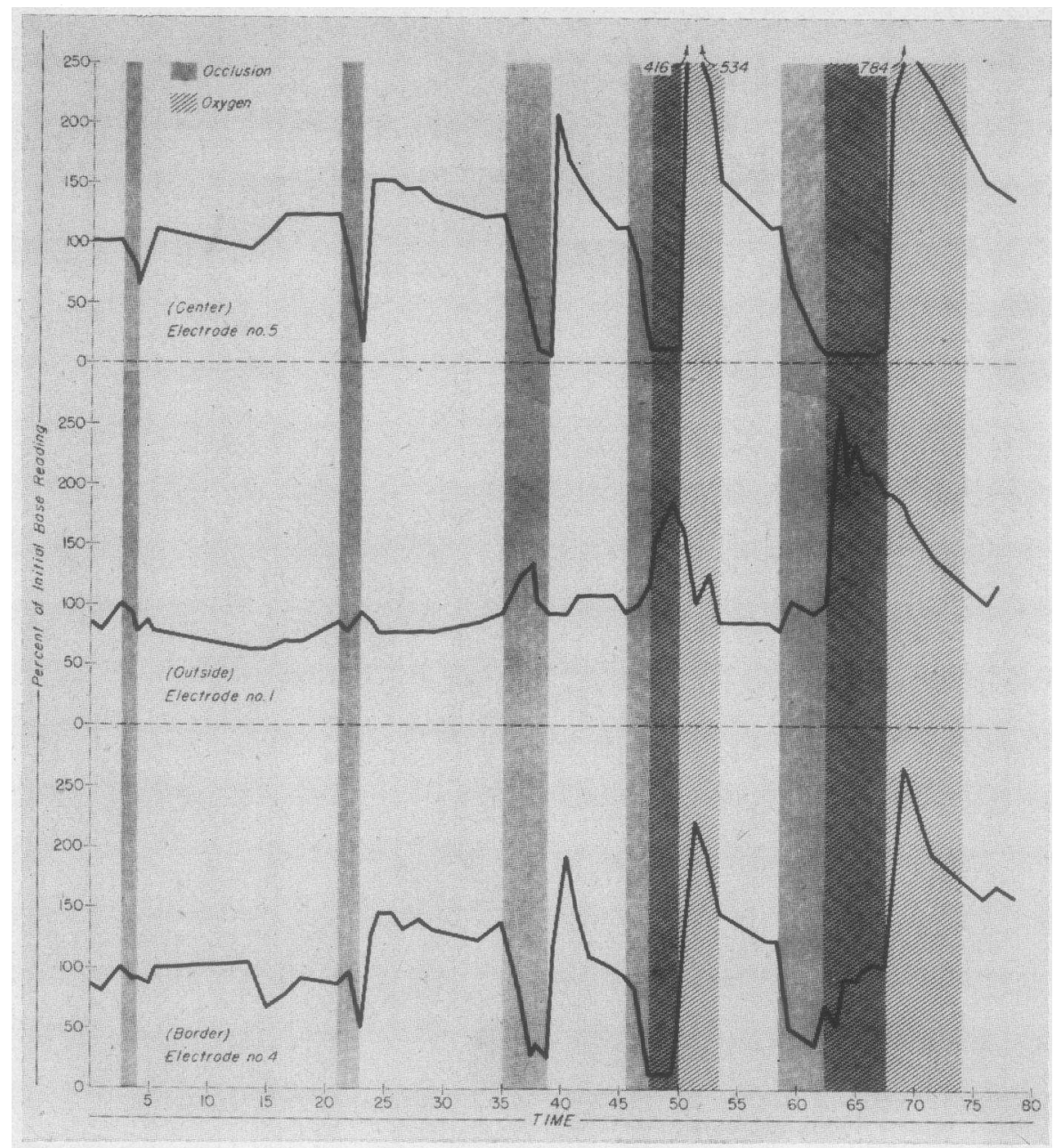

Fig. 5. Graph of 60 Values Read on the Galvanometer from Each of Three ElecTRODES Throughout EXPERIMENT XXXII.

Time is given in minutes from an arbitrary zero, just after which the base line value taken as $100 \%$ was selected. Occlusion is denoted by gray coloration, pure oxygen inhalation by cross-hatching, and oxygen during occlusion by superimposition of these. The first occlusion was at B (see Figure 3). Its effects were considered too localized and the more proximal site $\mathrm{A}$ was selected for the subsequent occlusions. A late but significant rise at electrode 4 (border) before release of the occlusion can be seen at 49 minutes. A longer and greater rise occurs from 62 to 67 minutes at the same electrode. No determinations were made between 71 and 75 minutes, so that the graph's downward slope during the last three minutes of pure oxygen breathing is misleading. Readings were at approximately one minute intervals throughout the experiment but are not, of course, simultaneous since nine electrodes had to be read in rotation each time.

chance of variation in diffusion gradients. In any case the current record in a myocardial electrode is the resultant of multiple factors including convection currents, the proximity of high capacity sources of oxygen such as red cells and alterations of the shape of the oxyhemoglobin dissociation curve by $\mathrm{pH}$ or temperature. Muscle contraction, with presumably intermittent oxygen utilization, must be a factor in the beating heart but the slow response of the d'Arsonval galvanometer does not permit study of such rapid fluctuations. Indeed, currents associated with cardiac excitation might prove difficult to distinguish from those due to oxygen reduction should a more rapidly responsive instrument be employed.

The interplay of all these influences makes the 
platinum electrode of uncertain value at present for quantitative study of changes in the heart as a whole or the comparison of readings widely spread in time. Nevertheless it is a great advantage to have multiple and rapid or, if desired, continuous estimations of available oxygen when studying localized myocardial ischemia.

It is possible to make a "physiologic" division of the electrode areas according to their behavior during repeated occlusions rather than the "anatomic" division adopted for the initial correlation. Based on the mean of the greatest changes from the last control value during occlusions without oxygen and the pre-oxygen period of the other occlusions for each electrode, three myocardial zones can be differentiated. The characteristics of these physiologic areas are summarized in Table II. Figure 6 shows the electrodes assigned to "physiologic" groups, and the inferred extent of the "central" and "border" zones. Comparison with Figure 3 makes it clear that neither distribution is incompatible with the epicardial coronary distribution and the observed extent of the grossly ischemic areas.

Since the "border" areas cannot be sharply defined and their behavior cannot be predicted on purely anatomic grounds, the physiologic grouping seems to have advantages for describing the character of localized ischemic areas in the myocardium. It can be stated on the basis of our data so far that during short occlusions electrodes which fall significantly (more than 15\%) but not below one-fourth of the base line value have shown rises on pure oxygen breathing during occlusion in $68 \%$ of instances. The majority of these rises have been greater than $25 \%$ of the baseline figure for the particular electrode. At areas showing falls to less than one-fourth of the base-
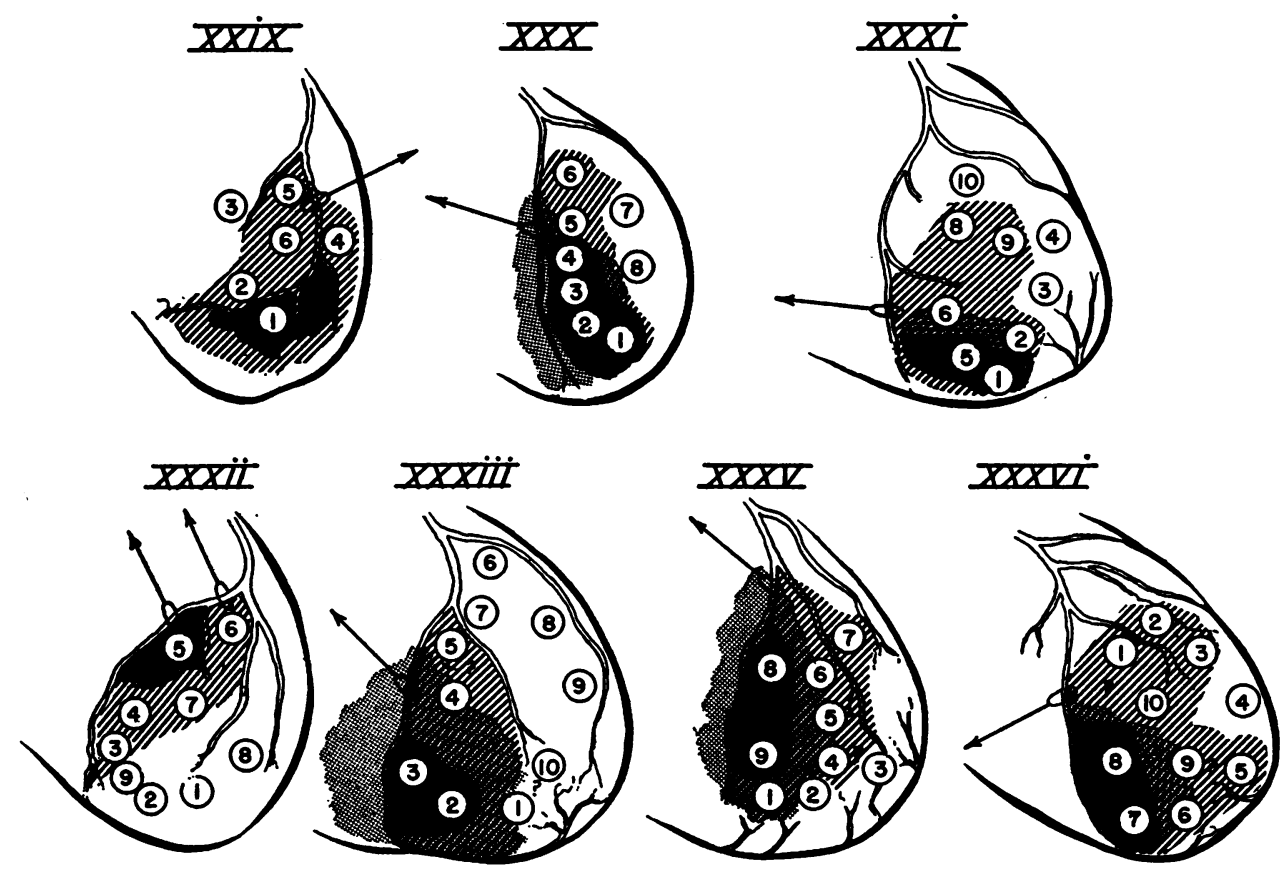

Fig. 6. The Approximate Extent of "Physiologic" Central (Dark) and Border (Hatched) Zones, Based on the Mean of Maximal Changes in Electrode Readings at Each Position During Coronary Occlusion

The electrode position, coronary pattern and visible extent of ischemia (light shading) are identical with Figure 3, to which this figure should be compared. See text and Table II for further explanation. It is noteworthy that in experiments XXXI, XXXV and XXXVI electrode behavior indicates occlusion or stenosis of the coronary ramus at a higher point than the anatomic position of the ligature. This would not be impossible, because strong traction was used to produce occlusion. We are inclined to think that the electrode behavior reflects the actual consequences of experimental occlusion better than the "anatomic" classification of electrode areas shown in Figure 3. 
line values, rises during oxygen breathing occurred in $22 \%$ of instances during occlusion with only a single instance of a rise larger than $25 \%$. Areas in which electrode values rose with coronary occlusion or fell insignificantly were characterized by rises during oxygen breathing in $88 \%$ of instances, most of them greater than $25 \%$.

It had not been established previous to our preliminary report that intramyocardial oxygen availability increases with pure oxygen breathing in a manner similar to that observed in human skin (2). How great an advantage to the normal myocardium this is remains conjectural at present, but the presumption must be that some portions of the borders of myocardial infarcts will remain viable as a result of pure oxygen inhalation. How large these areas may be would seem to depend on the severity of the ischemia, the length of the ischemic period, and the duration of increases in oxygen availability. The occlusions we have studied so far have been too brief to decide this question. Studies of the effect of oxygen inhalation on ischemic areas in the distribution of a narrowed rather than an occluded coronary vessel permit longer periods of observation. We believe this situation resembles many which occur in man. These studies, which are nearing completion and have been reported in an abstract (5) include correlation with epicardial electrocardiograms. They have shown that in "physiologic" border areas the increases of oxygen availability are well maintained during periods of coronary narrowing and are accompanied at least occasionally by diminution in electrocardiographic abnormality. The occasional rises recorded at "central" areas are transient. Fifty per cent oxygen inhalation has proved greatly inferior to pure oxygen in achieving favorable results. Preparations based on coronary narrowing lend themselves much better to studies of the effect of drugs on the heart during localized ischemia. These studies are in progress.

\section{SUMMARY AND CONCLUSIONS}

A polarographic technique for multiple, rapid, and relatively simultaneous estimations of local oxygen availability in the dog's left ventricular muscle has been described, together with some results of its application to the study of brief coronary occlusions. Electrode responses during coronary occlusion permit differentiation of three myocardial zones: (1) "Central" areas which show rapid decreases in available oxygen to less than a quarter of the base line values; (2) "Border" areas where falls are slower and less profound; (3) "Outside" areas showing no significant decrease in available oxygen. This physiological classification of myocardial areas has been consistent with the gross appearance of the heart when the borders of the ischemic areas are clearly discernible.

When pure oxygen inhalation is begun during coronary occlusion "outside" areas show the large and prompt rises of electrode readings characteristic of "normal" muscle, rises in "central" areas are rare and slight, while in "border" areas onethird of the initial fall is regained in two-thirds of instances. This statistically significant increase in available oxygen in border zones after pure oxygen breathing is begun, and before the occlusion terminates, supports the belief that inhalation of high concentrations of oxygen may reduce the extent of muscle necrosis resulting from coronary occlusion in man.

\section{REFERENCES}

1. Horwitz, O., Saÿen, J. J., Sheldon, W. F., and Kuo, P. T., Experimental studies of intramyocardial oxygen tension: Increases consequent on breathing pure oxygen in normal hearts and at the borders of ischaemic areas. J. Clin. Invest., 1950, 29, 823.

2. Montgomery, H., and Horwitz, O., Oxygen tension in the skin of extremities. J. Clin. Invest., 1948, 27, 550.

3. Davies, P. W., and Brink, F., Jr., Microelectrodes for measuring oxygen tension in animal tissues. Rev. Scient. Instruments, 1942, 13, 524.

4. Montgomery, H., and Horwitz, O., Oxygen tension of tissues by the polarographic method. I. Introduction: oxygen tension and blood flow of the skin of human extremities. J. Clin. Invest., 1950, 29, 1120.

5. Saÿen, J. J., Sheldon, W. F., Zinsser, H. F., Kuo, P. T., Horwitz, O., and McCallie, D. L., Studies of coronary disease in the experimental animal. III. Polarographic studies of intramyocardial oxygen availability in dogs with acute coronary occlusion and narrowing correlated with epicardial electrocardiograms. J. Clin. Invest., 1951, 30, 670. 